\title{
A diplomacia dos armamentos em Santiago: 0 Brasil e a Conferência Pan-Americana de 1923
}

Eugênio Vargas Garcia

Diplomata - Universidade de Brasília

RESUMO

$\mathrm{O}$ artigo examina o encaminhamento dado pela diplomacia brasileira à questão dos armamentos navais entre os países do ABC (Argentina, Brasil e Chile) durante a Conferência Pan-Americana de 1923 em Santiago. Por acreditar que estava em situação de inferioridade estratégica, o Brasil desejava preservar sua autonomia nos assuntos de defesa e era por isso acusado de militarismo. As negociações sobre a chamada tese XII terminaram em impasse e, ao final da Conferência, o Brasil se viu virtualmente isolado na região.

Palavras-chave: Política Externa Brasileira. Conferência Pan-Americana de 1923. Armamentos Navais.

\section{ABSTRACT}

The article examines how Brazilian diplomacy dealt with the question of naval armaments among the $\mathrm{ABC}$ countries (Argentina, Brazil and Chile) during the 1923 Pan American Conference in Santiago. Thought to be in a position of strategic inferiority, Brazil aimed at preserving its autonomy in defense affairs and, for this reason, it was accused of militarism. Negotiations on the so-called Thesis XII ended in a stalemate and, by the end of the Conference, Brazil found itself virtually isolated in the region.

Keywords: Brazilian Foreign Policy. Pan American Conference of 1923. Naval Armaments.

\section{INTRODUÇÃO}

Na década de 1920, o tema do desarmamento saiu dos círculos fechados das discussões acadêmicas e entrou para a ordem do dia como uma exigência da opinião pública. A Primeira Guerra Mundial havia deixado um saldo trágico de milhões de mortos, feridos e inválidos. A carnificina provocada pelos quatro anos e meio de conflagração deu origem a profundo sentimento contrário à guerra entre as populações atingidas, que clamavam pela paz definitiva entre os povos e o fim da insanidade das armas. 
Esse estado de ânimo também se fez sentir na América do Sul, onde rivalidades históricas se somavam a preocupações recíprocas entre os países da região a propósito das forças militares e das intenções belicosas de cada um. A questão dos armamentos navais em particular, objeto de análise neste artigo, voltou a ocupar espaço na agenda regional, com destaque para o problema dos encouraçados entre Argentina, Brasil e Chile. Fricções freqüentes e recriminações mútuas ameaçavam as boas relações entre países vizinhos que a rigor não tinham motivos reais para iniciarem guerras uns contra os outros. A imprensa insuflava paixões nacionalistas enquanto os governos agiam no campo diplomático para contra-arrestar ameaças que acreditavam existir. A situação atingiria seu ponto crítico em 1923, por ocasião da Conferência Pan-Americana de Santiago (referida oficialmente como a V Conferência Internacional Americana), a partir da sugestão chilena de colocar em discussão a redução e/ou limitação dos gastos militares e navais no continente (a chamada tese XII). ${ }^{1}$

A posição do Brasil provocou polêmica entre os contemporâneos, pois, partindo de uma avaliação de desvantagem do país em relação às forças armadas da Argentina e do Chile, o governo brasileiro se manifestava em geral contra as propostas de desarmamento que limitassem sua capacidade de defesa aquém do patamar considerado minimamente necessário. Além disso, o Brasil estava empenhado em levar a cabo planos de modernização militar, auxiliado pela Missão Militar francesa junto ao Exército e pela Missão Naval norte-americana no caso da Marinha, fato que gerava inquietações nos países vizinhos.

Este artigo tem por objetivo examinar a evolução do debate na época e o desenrolar das negociações sobre armamentos na Conferência de Santiago, onde o Brasil procurou fazer valer seu ponto de vista. O texto está estruturado em quatro partes principais: antecedentes da questão dos armamentos; as negociações preliminares e a malograda proposta brasileira de uma reunião prévia em Valparaíso entre os países do ABC; o desenvolvimento da Conferência propriamente dita; e as repercussões no contexto regional, incluindo a atitude dos Estados Unidos diante da hipótese de uma corrida armamentista entre o Brasil e a Argentina.

\section{ANTECEDENTES DA QUESTÃo DOS ARMAMENTOS}

\subsection{O balanço estratégico entre as forças navais do $A B C$}

O equilíbrio estratégico sul-americano girava basicamente em torno dos três países da região mais preparados no campo militar: Argentina, Brasil e Chile. Já antes da Primeira Guerra Mundial, a competição naval entre os paí- 
ses do $\mathrm{ABC}$ havia causado sobressaltos no continente. O programa naval de 1906 do Brasil previa originalmente, entre outros navios, a aquisição de três encouraçados, a serem construídos na Grã-Bretanha: Minas Gerais, São Paulo e Rio de Janeiro. Os navios seguiriam o modelo revolucionário aplicado ao recém-lançado H.M.S Dreadnought, de última geração. Os dois primeiros foram entregues em 1910. O terceiro deles, no entanto, por dificuldades orçamentárias, seria vendido à Turquia, em 1913, enquanto ainda estava em construção. Implementado à época do barão do Rio Branco como titular do Itamaraty, o programa provocou acesa controvérsia no plano regional, gerando críticas e suspeitas da Argentina, que defendia o princípio da equivalência naval entre os países sul-americanos.

Em conseqüência, a Argentina encomendou dos Estados Unidos, em 1910, a construção de dois encouraçados para fazer frente aos navios brasileiros: o Moreno e o Rivadavia. Em resposta ao reaparelhamento naval que os dois países promoviam, especialmente seu vizinho transandino, o Chile firmou contrato, em 1911, para a compra de dois encouraçados da Grã-Bretanha, reduzidos a apenas um devido à guerra e efetivamente entregue somente em 1920: o Almirante Latorre. A corrida por armamentos navais na América do Sul, estimulada pela rivalidade regional e por feroz competição entre firmas estrangeiras para a obtenção de novas encomendas, perderia intensidade com o aperto financeiro dos países do ABC e a eclosão do conflito mundial em 1914, que desviou a atenção dos principais estaleiros internacionais para o esforço de guerra. ${ }^{2}$

No pós-guerra, o diagnóstico corrente nos círculos militares e navais brasileiros era de inferioridade do Brasil em relação às forças de seus principais competidores sul-americanos. Se comparados os efetivos militares permanentes (praças e oficiais) com as populações dos países do $\mathrm{ABC}$, o resultado seria o seguinte: 1,5 homens no Brasil para cada mil habitantes, 3 na Argentina e 5 no Chile. Um estudo secreto do Estado-Maior do Exército sobre a situação militar na América do Sul, de dezembro de 1922, mostrou que enquanto o Brasil podia mobilizar em caso de guerra apenas duas divisões de artilharia, a Argentina poderia contar com cinco delas. A Argentina teria orçamento de guerra superior ao do Brasil, pessoal combatente em maior número e melhor instruído, além de capacidade mais rápida de mobilização. Tudo facilitaria para uma invasão do Brasil pelas forças argentinas: as linhas férreas, as estradas e os caminhos fluviais, que "serviriam, com imenso proveito, de linhas de transporte para nossa fronteira em caso de invasão."

O capitão-de-mar-e-guerra Armando Burlamaqui, discursando na Câmara dos Deputados, concluiu que proporcionalmente o Brasil era o país que menos gastava com forças armadas no $\mathrm{ABC}$. No tocante à Marinha, o Brasil estava "sempre aquém de suas reais necessidades, e muito abaixo do nível em que se 
colocaram e se acham as duas nações mais fortes do nosso continente". A tonelagem total da esquadra de guerra brasileira era de 59.193 (17 navios), ao passo que a Argentina tinha 108.375 toneladas (29 navios) e o Chile 79.528 (30 navios). O programa naval de 1906 não havia sido completado e o navio brasileiro mais moderno era de 1910. Em um período de rápida evolução da indústria naval, os encouraçados da Argentina e do Chile, construídos posteriormente, provaram ser ao final mais avançados do que seus similares brasileiros. Para Burlamaqui, o debate que se começava a travar não tinha razão de ser:

Não se achando armado, como não se acha presentemente, o Brasil não pode compreender que se fale em desarmamento. (...) Nem tampouco se pode falar em limitação de armamentos, porque nada temos que limitar, limitados como se acham, no mínimo, os nossos meios de defesa no mar. ${ }^{3}$

Nesse contexto, o Brasil se amparava no artigo $8^{0}$ do Pacto da Liga das Nações, pelo qual os Estados-membros reconheciam que a manutenção da paz exigia a "redução dos armamentos nacionais ao mínimo compatível com a segurança nacional e com a execução das obrigações internacionais impostas por uma ação comum." A tese do "mínimo compatível” seria retomada em diversas ocasiões. O argumento brasileiro se baseava na percepção de que o país estava em condições muito diferentes das grandes potências, que haviam renovado seu material bélico e aprimorado enormemente sua técnica militar durante a Primeira Guerra Mundial. Aquelas nações estariam "superarmadas" e fazia sentido neste caso falar em "desarmamento", atendendo ao apelo universal pela paz. O mesmo não podia ser dito do Brasil, que possuiria orçamentos militares e navais muito reduzidos e forças armadas insuficientes para as necessidades de segurança do país. Com essa linha de argumentação, o governo brasileiro esperava bloquear as propostas que tolhessem sua liberdade de ação estratégica, mesmo que para tanto precisasse desempenhar o papel de opositor ferrenho do desarmamento. Este era o dilema brasileiro no pós-guerra: o choque de realismo trazido pela guerra fez parecer urgente a necessidade de modernização militar do país em um contexto internacional que apontava em sentido oposto, ou seja, que os países deveriam se desarmar e buscar a paz a qualquer custo. A tentativa de superação desse dilema estaria na raiz de muitas dificuldades da diplomacia brasileira na década de 1920.

\subsection{A Conferência Naval de Washington (1922)}

Em 1921, ausentes da Liga das Nações, os Estados Unidos haviam decidido convocar uma Conferência em Washington, a iniciar-se em novembro 
daquele ano, a fim de discutir o desarmamento naval e a questão do Extremo Oriente. A iniciativa foi tomada em momento bastante favorável: além de atender aos reclamos populares pelo fim da corrida aos armamentos, permitiria aos Estados Unidos renegociar os termos de seu novo papel como potência marítima de primeira grandeza e encaminhar seus interesses estratégicos no Pacífico, onde o Japão havia sido largamente beneficiado pela guerra mundial. $\mathrm{O}$ governo norte-americano atribuía prioridade à contenção das tendências expansionistas japonesas tanto na esfera naval quanto em relação à China. Com essas preocupações em mente, o presidente Warren Harding limitou o convite à Conferência apenas às principais potências marítimas (GrãBretanha, Japão, França e Itália) e a países específicos com interesses na Ásia (Países Baixos, Bélgica e Portugal), além da própria China.

Presidida com energia pelo secretário de Estado norte-americano, Charles Evans Hughes, a Conferência Naval de Washington aprovou, em 6 de fevereiro de 1922, um tratado de fixação de limites máximos de tonelagem para as esquadras das maiores potências marítimas, com base na seguinte proporção: 5 para os Estados Unidos, 5 para a Grã-Bretanha, 3 para o Japão, 1,75 para a França e 1,75 para a Itália. Vários navios já existentes seriam efetivamente desmantelados. Os programas de construção naval das potências contratantes deveriam ser suspensos por dez anos e os navios capitais não poderiam ultrapassar o limite de 35.000 toneladas para cada unidade, com canhões de calibre máximo de 16 polegadas.

Em setembro de 1922, as resoluções da Conferência no campo do desarmamento naval foram levadas a Genebra, durante a $3^{\underline{a}}$ Assembléia da Liga das Nações, ocasião em que os Estados-membros examinariam a possibilidade de extensão dos princípios do Tratado Naval de Washington às potências não signatárias. O presidente Epitácio Pessoa tomou para si a responsabilidade de emitir diretamente instruções aos delegados brasileiros e, em telegrama de 17 de setembro, comunicou a Domício da Gama, chefe da delegação, que o governo brasileiro não podia aceitar nenhuma solução que restringisse o poder naval do Brasil abaixo dos limites exigidos para a defesa de um país com 1.200 léguas de costa. A força atual do Brasil era "muito inferior às nossas estritas necessidades." Por isso, continuou Epitácio, era preciso "ampliá-la em justa medida, sem nenhum intuito que não seja garantir nossos portos e costas." $\mathrm{O}$ presidente brasileiro não aceitava os princípios da Conferência de Washington porque, segundo ele, as condições na Europa eram diversas daquelas na América do Sul.

Na 3ํㅗㄹ Assembléia, o debate se concentrou na comissão relativa aos armamentos, onde Raul Régis de Oliveira procurou expor, sem nenhum apoio dos países sul-americanos, a posição peculiar do Brasil e suas necessidades de se- 
gurança, recordando os termos do artigo $8 \infty$ do Pacto. Afirmou que cumpria não esquecer a dificuldade em defender um país de 30 milhões de habitantes e uma linha de costa quase igual à distância da Europa à América do Sul. A determinação brasileira em não se submeter aos princípios de Washington gerou um impasse e, como alternativa conciliatória, aprovou-se uma resolução convocando uma conferência para examinar o assunto, dando a atenção devida aos países em situação especial. Estariam incluídos nessa categoria todos os casos de países sem Marinha suficiente (caso do Brasil) ou de recente formação política (caso da Polônia). ${ }^{4}$

Ao analisar a questão meses depois, Hélio Lobo, então cônsul-geral em Nova York, avaliou que, vencedor em sua tese, o Brasil começou a aparecer perante o mundo como "o propugnador de armamentos, adversário de sua limitação e criador, na América do Sul, do princípio da paz armada." Segundo ele, o problema tinha uma dupla significação: a nacional, de "segurança militar", e a externa, de "realização diplomática." A incógnita na frente diplomática era a Argentina, "país supersensível nas suas relações internacionais", que seria talvez, na opinião do diplomata brasileiro, o ponto "mais delicado" nas relações exteriores do Brasil..$^{5}$

\section{As Negociações RUMO A SANTIAgo}

\subsection{As reuniões preparatórias em Washington e o surgimento da tese XII}

A IV Conferência Internacional Americana havia sido realizada em Buenos Aires, em 1910, ocasião em que o existente Bureau das Repúblicas Americanas foi transformado em União Pan-Americana (UPA). A conferência seguinte, marcada para 1914, em Santiago, não se realizou naquela data em função da eclosão da Primeira Guerra Mundial, permanecendo adiada até posterior sugestão do governo chileno de organizá-la em 1923. Para tanto, foram convocadas reuniões preparatórias na sede da UPA, em Washington, já que o programa original aprovado para 1914 precisava ser revisto e atualizado à luz dos acontecimentos dos últimos anos e das grandes transformações verificadas no cenário internacional.

Um dos itens do programa proposto pelo Chile, que viria a ser conhecido como a tese XII, dispunha que os países participantes iriam considerar a "adoção de uma convenção destinada a reduzir em proporção igual os gastos militares e navais." Muito se especulou na época sobre qual teria sido a motivação do Chile ao propor a inclusão da questão dos armamentos no programa da Conferência. Ecoavam ainda os recentes debates na Liga das Nações e, 
pensavam alguns, o governo chileno poderia ter tido meramente a intenção de colaborar de boa-fé com as nobres aspirações do desarmamento, levando o tema à consideração dos países americanos. Outros avaliaram que o Chile pretendia em realidade fazer um gesto de agrado aos Estados Unidos, tendo em vista a futura arbitragem norte-americana na questão de Tacna e Arica entre o Chile e o Peru. Como os Estados Unidos haviam defendido vigorosamente a limitação dos armamentos na Conferência Naval de Washington, a percepção corrente entre os contemporâneos era a de que o governo norteamericano estaria igualmente empenhado em promover iniciativas similares em outros foros.

No Brasil, iniciava-se o governo Artur Bernardes, que tomara posse em 15 de novembro de 1922. Como ministro das Relações Exteriores havia sido nomeado José Félix Alves Pacheco, jornalista e escritor, nascido no Piauí, que se tornou diretor e proprietário do Jornal do Commercio. Félix Pacheco não tinha experiência anterior em assuntos de sua nova pasta e precisava lidar de imediato com a questão candente dos armamentos.

Logo em 20 de novembro, Pacheco enviou telegrama de instruções ao embaixador do Brasil em Washington, Augusto Cochrane de Alencar, sobre como proceder no caso da tese XII. Consoante seu empenho pela paz e a arbitragem, observou Pacheco, o Brasil não era nem podia ser hostil à idéia do desarmamento. A "proporção igual” que se procurava só deveria ser aceita se fosse previamente declarado que ela seria estabelecida em função do tamanho territorial, do volume da população, da extensão da orla marítima a defender e da capacidade atual de mobilização. Outras "circunstâncias intuitivas" também entrariam em consideração, como a de que somente agora o Brasil estava pensando em organizar o seu Exército e sua Marinha, enquanto outros vinham "porfiada e ininterruptamente atendendo a esse imperioso dever." A questão do desarmamento escaparia à competência e aos fins para os quais haviam sido criadas as conferências pan-americanas. Para o chanceler brasileiro, os Estados americanos procuravam apenas prover as necessidades de sua segurança interna e externa, "sem nenhum pensamento oculto de hostilidade contra qualquer outra nação, não importa de que continente”. Mais tarde, Pacheco acrescentou que o Brasil precisava insistir "com jeito" no sentido de arredar definitivamente esse "tema ingrato", capaz de prejudicar a obra da Conferência ou quiçá dificultar sua própria realização. Todos os esforços para evitar semelhante "desastre" seriam beneméritos e Alencar deveria "pôr nisso todo seu empenho", contornando do melhor modo as dificuldades que ainda surgissem e "atraindo para o nosso lado os Estados Unidos."

Durante as reuniões preparatórias, Alencar defendeu ponto de vista contrário à proposta da tese XII e, diante da oposição brasileira, o Chile se mos- 
trou disposto a aceitar outra fórmula que eventualmente satisfizesse o Brasil. Tentando mediar a questão, Charles Hughes, que presidia os trabalhos, declarou que era "indispensável" a modificação da redação de algumas propostas, especialmente aquela relativa à redução dos armamentos "em proporção igual", comprometendo-se a preparar um substitutivo à tese chilena. Assim, em 6 de dezembro de 1922, foi enfim aprovada pelo Conselho Diretor da UPA a agenda para a Conferência de Santiago. Conforme o substitutivo Hughes, a idéia de "proporção igual” desaparecia para dar lugar à "consideração da redução e limitação de despesas militares e navais em uma base justa e praticável.” O Brasil concordou com essa redação para a tese XII por entender que ela era suficientemente vaga para permitir uma razoável margem de manobra quando surgisse o momento de lidar com a questão. ${ }^{6}$

\subsection{A proposta brasileira da Conferência Preliminar de Valparaíso}

Enquanto prosseguiam as reuniões preparatórias, Pacheco vislumbrou a hipótese de convocar uma conferência preliminar entre Argentina, Brasil e Chile, antecedendo a Conferência de Santiago, na tentativa de limitar o impacto 180 das discussões referentes ao desarmamento sobre a política militar e naval do Brasil. A intenção era restringir as negociações sobre os armamentos tão-somente aos principais interessados, isto é, os países do ABC. Pacheco pensava que a maioria das nações americanas não tinha interesse imediato no assunto nem precisava opinar sobre ele. Seria "mesmo perigoso" deferir à totalidade dessas nações a faculdade de decidirem a respeito com as três maiores potências da região, às quais caberia exclusivamente a discussão do problema.

Pacheco se cercou de cuidados antes de decidir pela proposta e, com a aprovação de Artur Bernardes, procurou conhecer a opinião dos Estados Unidos sobre a sua iniciativa. Indagado por Alencar a respeito, Hughes afirmou que nenhuma objeção tinham os Estados Unidos quanto à reunião dos três países para discutir a redução das despesas militares e navais. Ao contrário, o governo norte-americano encarava-a "com a mesma simpatia com que sempre viu e verá tudo quanto signifique eliminação da emulação de armamentos e a segurança da manutenção da paz." Com esse aparente sinal verde de Washington, o próximo passo seria sondar em caráter reservado a recepção da idéia junto aos dois países vizinhos. ${ }^{7}$

Havia plena confiança na resposta positiva do Chile. O embaixador do Brasil em Santiago, Silvino Gurgel do Amaral, vinha mantendo contatos freqüentes com o governo daquele país. O presidente chileno, Arturo Alessan- 
dri, chegou a sugerir a cidade de Valparaíso para o encontro. A dúvida maior residia na possível reação da Argentina.

Em $1^{\circ}$ de dezembro de 1922, o embaixador brasileiro em Buenos Aires, Pedro de Toledo, entrevistou-se com Tomas Le Breton, ministro interino das Relações Exteriores da Argentina, com vistas a discutir a proposta da conferência preliminar. Le Breton julgou útil a idéia, embora receasse que o entendimento entre as três maiores potências sul-americanas pudesse ferir suscetibilidades das demais nações irmãs do continente, fazendo suspeitar uma aliança ou a formação de um grupo dominante na América do Sul. Como alternativa, sugeriu: a) que se abrisse um escritório em Valparaíso para receber estudos feitos pelos países americanos sobre o desarmamento; ou b) que fossem preparados pelos países do ABC, "sem nenhuma convocação", planos técnicos de redução dos armamentos, reunindo-se depois seus representantes em Buenos Aires a fim de estabelecerem um acordo a ser submetido à ratificação da Conferência de Santiago. A posição argentina permanecia dúbia, entretanto, visto que, ao final do encontro, Le Breton afirmou que se o Brasil tomasse a responsabilidade do convite a questão ficaria simplificada em relação à Argentina: "Quando um amigo me convida para um jantar, não indago os convidados; aceito o convite", disse ele.

Um dia depois do encontro com Le Breton, Toledo era informado de que o presidente Marcelo T. de Alvear, depois de meditar sobre o delicado assunto, considerava que a reunião em Valparaíso, devido a seu caráter público e ostensivo de "exclusão das outras nações sul-americanas", certamente traria conseqüências desagradáveis tanto na política interna como na política externa, com a atitude de cada país levantando protestos que seriam amplamente explorados. As pequenas nações, sinceramente ou não, considerariam a união entre Argentina, Brasil e Chile, a fim de combinarem sobre armamentos, como uma espécie de "aliança de fortes contra os fracos para imporem a sua hegemonia." Não sendo essa a intenção das três nações, era preferível "evitar o perigo previsto, procurando outra forma de acordo menos solene e tal-

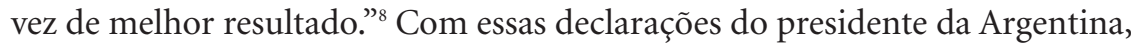
parecia claro, portanto, que a iniciativa brasileira era vista com muito pouca simpatia naquele país.

Não obstante, Pacheco havia entendido, erroneamente, que as objeções argentinas não eram de fundo, mas apenas de forma, e que havia concordância em princípio com a proposta brasileira. Assim, em 5 de dezembro, o governo brasileiro encaminhou convites formais à Argentina e ao Chile para uma Conferência Preliminar em Valparaíso, proposta para 15 de janeiro de 1923. A nota brasileira assinalava que o único propósito do encontro seria considerar, "com acentuada orientação pacifista", a situação em que cada país 
se encontrava quanto aos armamentos, para então ajustar um "entendimento cordial" a respeito, visando o mais depressa possível à fixação de uma base justa e prática que evitasse a progressão dos orçamentos militares.

O convite brasileiro foi recebido com surpresa em Buenos Aires. Em conversa reservada com o embaixador brasileiro, Le Breton aludiu à impressão que causara no presidente da Argentina o envio do convite formal antes da conclusão das negociações em andamento. Em 6 de dezembro, o governo argentino enviou sua resposta negativa, tornada pública dias depois. $\mathrm{O}$ texto fazia menção à dificuldade da Argentina em concorrer a reuniões parciais sobre temas que estariam destinados ao debate geral. Devia-se dar uma "oportunidade igual a todos os países da América" para intervir no estudo e na solução do problema. Essa oportunidade seria a própria Conferência de Santiago, ocasião em que a opinião dos outros países poderia também ser ouvida. Além disso, o tempo disponível era muito curto e a reunião de janeiro próximo seria "um tanto precipitada para a organização metódica que a importância do tema comporta."

O mal-estar criado entre o Brasil e a Argentina iria agravar-se ainda mais. Em 7 de dezembro, um artigo assinado por Jorge A. Mitre para o jornal $\mathrm{La}$ Nación qualificou de "inaceitável" a proposta brasileira de reduzir os arma182 mentos navais de forma proporcional à extensão das costas a defender. Segundo Mitre, essa teoria reeditava a política de "imperialismo pacífico e hegemonia efetiva" com que sonhara o barão do Rio Branco. Por mais extensas que fossem as costas brasileiras, isso não justificaria uma esquadra preponderante no continente, já que para a manutenção da paz no Atlântico Sul era essencial a equivalência naval argentino-brasileira. A tese do Brasil seria "mero pretexto, pueril e insustentável ante uma assembléia de homens sérios, para coonestar uma aspiração de superioridade." Os argentinos eram pacifistas, por sua tradição e sua história, mas seriam agora obrigados a rechaçar o convite brasileiro para a discussão dos armamentos por vir este acompanhado de uma precondição "totalmente contraproducente." Mitre concluiu seu artigo afirmando que a tranqüilidade sul-americana dependia do "equilíbrio e da equivalência potencial do ABC."

$\mathrm{O}$ artigo de Mitre desencadeou exaltado debate na imprensa argentina, invariavelmente contra a política do Brasil. La Razón citou militares argentinos que destacaram a situação inferior das forças armadas da Argentina em comparação com o Brasil e o Chile. Foram divulgados dados oficiais sobre a porcentagem dos gastos dos ministérios militares com relação aos orçamentos anuais em cada país: Argentina, 9,2\% (Guerra) e 7,5\% (Marinha); Brasil, $12,9 \%$ e $9,1 \%$; e Chile, $9,7 \%$ e 20,4\%. O jornal portenho criticou a tese da necessidade de uma "poderosa esquadra" para a defesa de suas costas, que o Bra- 
sil argumentava "para advogar sua supremacia marítima." Na África, por exemplo, havia países com costas extensas, mas nenhuma riqueza a defender. Propunha-se em contrapartida a idéia de basear o tamanho das esquadras não pela extensão das costas, mas pelo volume das exportações e importações em dólar de cada país. Ora, concluiu La Razón, a Argentina, cujo comércio exterior superava o brasileiro e o chileno, precisava de uma marinha maior do que seus vizinhos para a "custódia desta riqueza", sem mencionar sua "situação geográfica desfavorável”, que exigiria uma frota de guerra maior para a proteção de suas rotas marítimas. ${ }^{10}$

Os jornais argentinos denunciaram el imperialismo brasileño em matérias semelhantes que continuariam a ser publicadas meses a fio, em conexão com as negociações em Santiago. Pacheco observou a Pedro de Toledo, em 14 de dezembro, que todos os jornais no Brasil vinham sabendo guardar uma linha de moderação, a qual contrastava singularmente com "a violência e o espírito de intriga tão patentes nas folhas argentinas." No final daquele mês, o chanceler brasileiro lamentaria uma vez mais, desta vez a Domício da Gama, que toda a imprensa de Buenos Aires há mais de 20 dias não fazia outra coisa "senão agredir o Brasil."

O malogro da iniciativa da Preliminar de Valparaíso, jamais realizada, desconcertou a chancelaria brasileira, que passou à defensiva desde então. Diplomatas estrangeiros no Rio de Janeiro consideraram que Pacheco, ao enviar o convite, havia cometido uma gafe constrangedora devido à sua inexperiência nos métodos diplomáticos. ${ }^{11} \mathrm{O}$ Brasil teria agora de arcar com o ônus de enfrentar a crítica da opinião pública no continente, liderada pela Argentina, cujas autoridades ficaram indignadas com a notícia simultânea da chegada da Missão Naval norte-americana ao Brasil, como será visto a seguir.

\subsection{O impacto da Missão Naval norte-americana ao Brasil}

A exemplo do Exército brasileiro, que contratou em 1919 a Missão Militar francesa, a Marinha também buscou no exterior o auxílio de uma potência estrangeira para a instrução, modernização e reorganização da força naval brasileira. A escolha recaiu nos Estados Unidos, que venceram a disputa com a Grã-Bretanha pelo envio da missão. O contrato foi assinado em Washington, em 6 de novembro de 1922.

No âmbito regional, a divulgação da contratação da Missão Naval norteamericana teve efeitos devastadores, por ter ocorrido precisamente em meio à crise originada pela proposta brasileira da Preliminar de Valparaíso. Em meados de dezembro de 1922, recebia-se na Argentina a notícia de que a Mis- 
são estaria chegando no Rio de Janeiro ainda naquele mês. A reação nos círculos governamentais argentinos foi a pior possível. Irritado, Le Breton interpelou o embaixador norte-americano em Buenos Aires, John Riddle, sobre o significado daquela "missão naval oficial." Le Breton declarou que governo argentino estava "perplexo" e aludiu ao fato de que os Estados Unidos falavam em desarmamento ao mesmo tempo em que enviavam uma missão de reorganização da Marinha brasileira. A ação norte-americana decididamente parecia, se não um "ato hostil", uma expressão de "má vontade" em relação à Argentina, que ficaria assim obrigada a recorrer à Grã-Bretanha para instruir sua armada. Se um país era singularizado por favores desse tipo, caía por terra a solidariedade continental apregoada pelo governo de Washington, cuja atitude no caso não podia ser entendida, tanto mais que a Argentina havia antes adquirido seus dois encouraçados e armamentos navais nos Estados Unidos. Consternado, o ministro da Marinha argentino se sentiu pessoalmente ferido e quis saber qual seria a posição da Missão em caso de guerra, uma vez que seu caráter oficial indicava uma "aliança entre o Brasil e os Estados Unidos." 12

Em 21 de dezembro, Hughes explicou, em telegrama dirigido ao embaixador Riddle, que o propósito da Missão era meramente o de cooperar com as autoridades brasileiras para assegurar uma boa organização naval naquele país, melhorando os métodos de trabalho, treinando e instruindo oficiais, assim como elaborando planos para o aperfeiçoamento da Marinha. "Em caso de guerra civil ou de guerra entre o Brasil e qualquer outra nação nenhum membro da Missão, de acordo com os termos do contrato, tomará parte nas operações em absolutamente qualquer sentido", afirmou. O secretário de Estado acrescentou que outras potências tinham o hábito de despachar missões militares e navais quando solicitadas por governos estrangeiros. O envio da Missão Naval ao Brasil não representava, por conseguinte, uma nova política do Departamento de Estado e tampouco significava uma mudança no compromisso dos Estados Unidos com a solidariedade pan-americana. A forma do contrato obedecia simplesmente aos padrões oficiais rotineiros e aos precedentes na matéria. ${ }^{13}$ Riddle comunicou esses esclarecimentos às autoridades argentinas e divulgou em seguida uma nota à imprensa nos mesmos termos para aplacar a ira da opinião pública naquele país. Os Estados Unidos tentaram ao máximo diminuir a importância da Missão, a fim de reduzir o seu custo político junto ao governo argentino. Na abordagem global de Washington para os assuntos sul-americanos, não convinha absolutamente avançar na cooperação naval com o Brasil queimando pontes com a Argentina.

A imprensa argentina aproveitou para acentuar o caráter contraditório da Missão Naval em meio a conferências de paz e de desarmamento. O jornal 
La Prensa observou que mesmo se o Brasil não desejasse ocupar o primeiro lugar como potência militar e naval na América do Sul, era "evidente" que suas ações seguiam "algum plano político”. A chegada da Missão se dava no mesmo ano da Conferência Naval de Washington e em poucos meses teria lugar a Conferência Pan-Americana de Santiago. Muitos não conseguiam entender o motivo pelo qual o Brasil parecia ansioso e determinado a melhorar sua Marinha em época tão pouco propícia a iniciativas que denotassem preparação para uma guerra eventual, ainda mais levando em conta a delicada situação financeira do país, acossado pelos déficits comerciais resultantes da aguda crise econômica do pós-guerra. As queixas e desconfianças recíprocas entre os dois maiores países sul-americanos indicavam maus presságios para a Conferência vindoura em Santiago.

\section{A Conferência Pan-Americana de Santiago}

\subsection{As primeiras negociações sigilosas e a Comissão de Armamentos}

A agenda da Conferência trazia um número recorde de temas, alguns deles de cunho eminentemente político. Não enviariam delegações a Santiago o México, cujo governo de Álvaro Obregón não era reconhecido pelos Estados Unidos, bem como o Peru e a Bolívia, que estavam de relações cortadas com o Chile desde a Guerra do Pacífico e com ele mantinham conflitos pendentes (questão de Tacna e Arica no caso peruano e da saída para o mar no caso boliviano).

Como chefe da delegação brasileira foi nomeado Afrânio de Melo Franco, deputado federal por Minas Gerais e antigo amigo e aliado de Artur Bernardes na política mineira. Félix Pacheco havia sido convidado pelo governo chileno para ir a Santiago, bem como pelo governo argentino para ser "hóspede de Estado" em Buenos Aires, por ocasião de sua passagem a caminho do Chile. O chanceler brasileiro, porém, recusou os dois convites e apresentou suas escusas por não poder aceitá-los, alegando "fortes motivos" que reclamavam sua permanência no Rio de Janeiro.

Em 11 de março de 1923, véspera da partida da delegação, Pacheco ofereceu um almoço de despedida no Hotel Glória e, em seu discurso naquele dia, destacou a franqueza e a boa-fé com que o Brasil comparecia a Santiago, "sem a mínima idéia de hostilidade contra ninguém e alheando-nos em absoluto de qualquer preocupação de hegemonia." O Brasil não levava nenhuma idéia preconcebida para aquela "palestra de amigos." Tal era a correção de conduta da diplomacia brasileira, assinalou, que a delegação não recebera ins- 
truções escritas da chancelaria. Bastariam as recomendações do governo que ora o seu ministro das Relações Exteriores expedia de público. ${ }^{14}$

A caminho de Santiago, a delegação brasileira passou pelo Uruguai, onde foi recebida com frieza, o que fez Melo Franco suspeitar que a "desusada rapidez da escala do navio em Montevidéu [meia hora] tivesse obedecido a ordens do governo oriental", pelo receio de desgostar a Argentina, da qual "os uruguaios dia a dia se vão fazendo vassalos". Em Buenos Aires, depois de alguns dias de espera e uma audiência protocolar com o presidente Alvear e o chanceler Angel Gallardo, a delegação partiu em seguida para o Chile, no mesmo trem em que também viajaram delegados argentinos, norte-americanos, uruguaios e paraguaios. Durante o longo percurso transandino, as delegações estiveram em contato forçado por quatro dias, prevalecendo, naquelas circunstâncias, as regras usuais de civilidade.

Uma vez na capital chilena, um dia antes de se iniciar a Conferência, Melo Franco e outros delegados brasileiros foram recebidos no Palácio La Moneda pelo presidente Alessandri e o novo ministro das Relações Exteriores, Luis Izquierdo. Melo Franco alertou o mandatário chileno sobre a existência de "força oculta interessada em perturbar a obra da Conferência." Alessandri, por seu turno, recordou a "tradição ininterrupta da política de profunda ami186 zade" entre Chile e Brasil e fez uma sugestão "em caráter confidencialíssimo": se Bernardes quisesse ter um encontro com ele e os presidentes da Argentina e do Uruguai, em Montevidéu, o Chile tomaria a iniciativa de promover essa reunião. Melo Franco transmitiu imediatamente a sugestão ao Itamaraty. ${ }^{15}$

A sugestão chilena para um encontro de cúpula em Montevidéu foi recebida com interesse pelo governo brasileiro. Era mais urgente, porém, definir a estratégia brasileira para as negociações em Santiago sobre a questão dos armamentos. Em telegrama a Melo Franco, Pacheco propôs duas saídas: a) abstenção pura e simples; ou b) uma declaração dizendo que o Brasil iria examinar "com bom espírito" o que a Conferência resolvesse, "dando de tudo conhecimento, no devido tempo, ao Congresso Nacional, a quem a nossa Constituição reservou a competência exclusiva de fixar as forças de terra e mar.” ${ }^{16}$ O governo brasileiro queria, no máximo, a aprovação de uma fórmula teórica ou texto genérico que afirmasse solenemente não estarem os Estados americanos se armando uns contra os outros e que cogitavam de Exército e Marinha apenas para atender às exigências de segurança interna e defesa. Para isso, o Brasil precisaria provar que não pretendia a superioridade militar sobre a Argentina e o Chile, sem ao mesmo tempo se deixar amarrar por um acordo que limitasse seus planos de reorganização das forças armadas.

A Conferência teve início em 25 de março de 1923, com uma sessão solene no salão de honra do Congresso chileno, inaugurada por Alessandri com 
um discurso de exaltação ao legado histórico e às virtudes do pan-americanismo. No dia seguinte, realizou-se a primeira sessão plenária da Conferência, sob a presidência do chanceler Izquierdo. Foram então constituídas oito comissões para a discussão dos tópicos do programa: política, jurídica, higiene, comunicações, comércio, agricultura, limitação de armamentos e educação. A tese XII seria discutida na Comissão de Armamentos, presidida por Henry Fletcher, chefe da delegação dos Estados Unidos. O relator da Comissão seria o delegado chileno Antonio Huneeus. No entanto, dada a controvérsia do tema, as delegações evitaram deliberadamente reunir a Comissão e a atividade nos primeiros dias se concentrou em démarches paralelas.

Em 28 de março, Melo Franco transmitiu a Alessandri os "entusiásticos aplausos" de Bernardes pelo discurso de abertura e a concordância em princípio do governo brasileiro com a proposta da cúpula de presidentes do Cone Sul. Sobre a tese XII, Alessandri confessou que o Chile não a teria proposto se tivesse previsto todos os fatos posteriores. Naquele momento, o objetivo primordial do governo chileno era evitar o naufrágio da Conferência em função das divergências sobre armamentos.

Dois dias depois, o chefe da delegação chilena, Agustin Edwards, convidou Melo Franco e Fletcher para uma conversa a três, enfatizando que urgia encontrar uma solução concreta para a questão. Melo Franco defendeu a posição brasileira e, segundo as instruções do Rio de Janeiro, declarou que o Brasil preferia abster-se da discussão, limitando-se à entrega de uma declaração escrita com o seu ponto de vista. O governo brasileiro seria favorável, mesmo assim, a uma fórmula geral sobre o desarmamento, sem tratar especificamente de reduções de orçamentos militares.

Enquanto prosseguia a Conferência, a opinião pública na Argentina continuava a criticar o Brasil, como vinha fazendo desde dezembro de 1922 . O jornal La Prensa, em editorial de 31 de março, afirmou que escritores abalizados no Rio de Janeiro atribuíam a Epitácio Pessoa o que chamaram de "ofensiva militarista contra a Argentina", fazendo menção à contratação da Missão Militar francesa e à Missão Naval norte-americana. Em seu mandato, notou o jornal, o ex-presidente brasileiro havia precipitado a preparação militar "de maneira extraordinária, ganhando dias, como se um inimigo estrangeiro estivesse já em marcha sobre as fronteiras de sua pátria." ${ }^{17}$

Melo Franco se queixou da "imprevista e descabida campanha promovida pela imprensa argentina contra o Brasil", que havia criado uma "falsa atmosfera de hostilidade" e de desconfiança para com os propósitos do governo brasileiro na política internacional hemisférica. Além de obstruir o debate e emperrar a solução do problema da tese XII, o Brasil era acusado de ter sido tomado de "paixão militarista", a qual teria ficado patente com a "espeta- 
culosa exibição", durante as festas do Centenário da Independência em 1922, de "luzidas e numerosas tropas de parada, em que avultavam, ao lado de armas conhecidas, os novos tanques e os aviões de guerra de terra e mar, cujas descobertas e aperfeiçoamentos se tinham assinalado na grande guerra de 1914-1918”. Em Santiago, Fletcher confidenciou em particular a Melo Franco que, nos Estados Unidos, também se atribuía ao Brasil "desejo de manter uma posição ostensiva de superioridade e hegemonia entre os seus irmãos latinoamericanos." ${ }^{18}$

A delegação argentina, chefiada por Manuel Augusto Montes de Oca, defendia uma solução que implicasse compromisso efetivo com a redução ou limitação dos armamentos. Como o Brasil se opunha a isso, o assunto não evoluía. Huneeus, a quem competia redigir um parecer à Comissão, buscou aproximar as duas delegações e convidou Melo Franco para um encontro, no dia 4 de abril, com Montes de Oca e Fernando Saguier, também membro da delegação argentina. Os resultados foram nulos. Em 6 de abril, a Comissão de Armamentos se reuniu, pela primeira vez, para ouvir que o relator não possuía ainda elementos para o seu parecer e que seria preciso, por isso mesmo, adiar a matéria. Entrementes, a pedido de Edwards, Melo Franco preparou um arrazoado que poderia servir de base a uma declaração futura sobre a tese XII. Vários dias se passaram, em marchas e contramarchas confidenciais, até que, em 11 de abril, Huneeus apresentou finalmente sua ponencia à Comissão, baseada em alguns pontos no documento que Melo Franco lhe dera a conhecer a título pessoal e em total sigilo.

Depois da apresentação do parecer Huneeus, que não se afastava muito do que pensava a delegação brasileira, os jornais argentinos passaram a atacar também o Chile, acusando-o de se achar preso ao Brasil por um "tratado secreto." Não havia tratado algum, mas a freqüência dos contatos do chefe da delegação brasileira com o presidente chileno parecia indicar que existia de fato estreita coordenação entre os dois países na Conferência. Em nova audiência com Alessandri, este declarou a Melo Franco que reconhecia as necessidades especiais de defesa do Brasil, cujo poder militar era mesmo inferior ao de seus vizinhos, e que se sentia "com coragem de dizer estas verdades ao presidente Alvear." Na opinião de Alessandri, a recusa argentina da Preliminar de Valparaíso havia sido um "profundo erro", daí sua sugestão de realizar-se uma reunião de cúpula em Montevidéu. O que a Argentina temia não era propriamente o aumento do atual poder brasileiro, mas a "indeterminação desse aumento". O presidente chileno acreditava que se o Brasil desse a conhecer o limite a que aspirava "o alarma argentino cessaria."

Em 14 de abril, o delegado de Honduras, Benjamin Villaseca Mujica, por iniciativa própria, propôs que a Conferência recomendasse dois pontos aos 
governos do continente: $1 \infty$ ) declarar como princípio de solidariedade continental que todos os povos da América consideravam as suas instituições armadas como tendo por único objetivo o resguardo da sua soberania nacional; e $2 \infty$ ) que a fim de chegar a acordos políticos em matéria naval, os governos do $\mathrm{ABC}$, principais interessados, resolveriam sobre os detalhes técnicos de um convênio sobre o assunto. O delegado hondurenho acrescentou que a questão das forças terrestres devia ser excluída por enquanto do debate e que seria prematuro se a Conferência se pronunciasse sobre ela. Esse critério seria reforçado por diversos fatores: "A escassa população, a enorme distância geográfica, a dificuldade dos meios de comunicação e o aforismo técnico de que o domínio do mar resolve os conflitos armados.” A proposta convinha ao Brasil e, percebendo isso, os argentinos desconfiaram que o delegado hondurenho agira em conluio com a delegação brasileira. Mesmo sem participação alguma na iniciativa, o Brasil com tato passou a defendê-la na Comissão. ${ }^{19}$

A exemplo de outras, a proposta de Honduras não vingou. Dentro do espírito de seu segundo ponto, contudo, Edwards confidenciou a Melo Franco que o governo chileno iria propor a limitação dos armamentos navais no $\mathrm{ABC}$ em 80.000 toneladas para os navios capitais, categoria que englobaria os cinco encouraçados existentes nos três países. Em resposta, Melo Franco retrucou que "preferíamos ver integralmente fracassada a Conferência a nos submetermos a imposições e medidas prejudiciais aos interesses supremos da nossa segurança e defesa." Diante dessa reação dura por parte do Brasil, Edwards adiou o anúncio público da proposta chilena, feita depois na Comissão de Armamentos sem referência ao limite máximo de tonelagem.

\subsection{Declarações de princípios, novas propostas e o acordo impossível}

Naquele estágio tenso da discussão da tese XII, a posição do Brasil parecia politicamente quase insustentável. Gurgel do Amaral reclamou que "embora sem motivo algum, o fato público e notório é que estamos considerados no estrangeiro, hoje mais do que nunca, graças a uma campanha de difamação caluniosa contra nós, como armamentistas e belicosos." Como a posição do Brasil na Conferência se deteriorava a cada dia, Artur Bernardes convocou uma reunião ministerial de seu gabinete para avaliar as alternativas diante do aumento da pressão internacional. Pacheco informou Melo Franco sobre a realização da reunião, na qual se decidira que o Brasil manteria sua linha de conduta observada até aquele momento. O Brasil, escreveu o chanceler, não queria "expor-se ao perigo de novas ciladas pela generalização impensada de um debate totalmente irrelevante para a maioria das nações representadas na Con- 
ferência e só dizendo respeito ao Brasil, Chile e Argentina." ${ }^{20}$ Pacheco orientou Melo Franco mais de uma vez a se abster do debate. Entretanto, o chefe da delegação brasileira achava que o momento político exigia a participação do Brasil e que a recusa em discutir o tema só faria agravar sua situação.

Assim, tendo antes enviado carta a Alessandri, prevenindo-o do fato, $\mathrm{Me}-$ lo Franco apresentou, na sessão de 21 de abril da Comissão de Armamentos, uma Declaração de Princípios em nome da delegação do Brasil, redigida por ele próprio. Já em sua primeira frase, o documento proclamava ser o supremo objetivo do Brasil "viver em paz com todos os povos do mundo." A declaração procurava enfatizar as tradições pacifistas do país, a prática do arbitramento e a "índole idealista" do povo brasileiro, de acordo com o espírito da Constituição de 1891, que estabelecia textualmente em seu artigo 88: "Os Estados Unidos do Brasil, em caso algum, se empenharão em guerra de conquista, direta ou indiretamente, por si ou em aliança com outra nação.” A preparação militar e a organização de sua defesa eram problemas que o Brasil só teria abordado seriamente a partir de 1916, em virtude da guerra mundial. Depois de destacar o tamanho modesto das forças de terra e mar do Brasil, em comparação com outros países da América do Sul, a declaração repassou o debate sobre o desarmamento no âmbito da Liga das Nações, explicando a posição brasileira 190 naquele foro. Em Santiago, apesar da precariedade de condições de sua Marinha, o Brasil não se furtara a debater o tema dos armamentos navais com as "Repúblicas americanas irmãs", embora achasse difícil encontrar uma "base única e igual" a ser aplicada a países de condições geográficas tão diferentes. Mesmo assim, a delegação do Brasil aceitaria um acordo que contemplasse a limitação da tonelagem dos navios capitais, por um período de cinco anos, a 80.000 toneladas. Concluía a declaração que o Brasil não se desligava dos compromissos que assumira e estava "pronto a negociar em qualquer tempo, de chancelaria a chancelaria, em ajuste com um ou mais países americanos irmãos, pactos de limitação de armamentos navais, sobre uma base justa e praticável, resguardadas as condições recíprocas da segurança nacional."21

Depois da leitura da Declaração de Princípios brasileira, Montes de Oca tomou a palavra e, após repetir por três vezes que a Argentina era a "campeã da arbitragem no mundo", apresentou à Comissão a contraproposta de seu governo: 55.000 toneladas para os navios capitais; 60.000 para os navios de guerra auxiliares de superfície; 25.000 para os navios porta-aviões; e 15.000 para os submarinos. O pomo da discórdia era a tonelagem dos navios capitais, o que levou a um confronto de números. Os dois encouraçados argentinos, o Moreno e o Rivadavia, deslocavam 27.000 toneladas, perfazendo um total de 54.000, dentro do limite proposto por Montes de Oca. Os encouraçados brasileiros, o São Paulo e o Minas Gerais, eram de 21.000 cada um, totali- 
zando 42.000 toneladas. Se o Brasil aceitasse o máximo de 55.000, o que sobrava (13.000) era insuficiente para outro navio capital. A proposta argentina, portanto, consagrava o statu quo, que o Brasil entendia lhe ser desfavorável. O teto comum de 80.000 toneladas, ainda que subscrevesse o princípio da equivalência naval, permitiria ao Brasil eventualmente adquirir novo encouraçado de 35.000 toneladas, limite estabelecido no Tratado Naval de Washington para cada navio capital. A Argentina não aceitava essa hipótese e, em conseqüência, as duas propostas pareciam irreconciliáveis.

Em 24 de abril, em mais uma tentativa de contornar o impasse e buscar uma solução consensual, Alessandri convocou os chefes das delegações do $\mathrm{ABC}$ para uma reunião no palácio presidencial e fez nova proposta, a ser aprovada sob a forma de recomendação pela Conferência. Dois prazos de acordo naval de cinco anos seriam estabelecidos: 1923-1928 e 1928-1933. Durante o primeiro prazo, a tonelagem máxima seria de 66.000 para os navios capitais, 85.000 para cruzadores e outros, e 15.000 para os submarinos. No segundo, o limite para os navios capitais subiria para 90.000 e os demais aumentariam em um terço. O presidente chileno chegou a apelar diretamente a Bernardes para que aceitasse os termos conciliatórios da solução chilena. Em telegrama ao Itamaraty, Melo Franco se manifestou contrário à proposta, mas como a delegação argentina se apressou em responder a Alessandri que tampouco a aceitava, coube à Argentina o ônus maior de mais essa frustração. ${ }^{22}$

Finalmente, em 30 de abril, Montes de Oca declarou na Comissão de Armamentos que a Argentina não desejava acordos que aumentassem as suas despesas militares e navais porque "a conseqüência seria a paz armada." Reafirmou que o governo argentino não aceitava a última proposta de Alessandri e, com isso, punha definitivamente "o ponto final" à questão. A saga da tese XII parecia ter chegado ao fim, uma vez que Melo Franco tinha a intenção de permanecer em silêncio, deixando as coisas como estavam. Contudo, neste momento, Gurgel do Amaral interveio para falar da existência de uma carta confidencial que ele havia entregue ao ex-chanceler chileno, Carlos Aldunate Solar, em 5 de dezembro de 1922, na qual o governo brasileiro informava acerca da idéia de condicionar o debate da tese XII à realização da Preliminar de Valparaíso. O Brasil, explicou o embaixador brasileiro, embora tivesse comparecido a Santiago por consideração ao país-anfitrião, acompanhado de oficiais e técnicos do Exército e da Marinha, sempre tivera o propósito de não discutir na Conferência a questão dos armamentos.

A delegação argentina se agitou e quis entender que se tramara um "pseudo-pacto secreto" entre o Brasil e o Chile, anterior à Conferência. Semanas de negociações teriam sido mera perda de tempo em função desse conchavo entre os dois países. Com estardalhaço, os argentinos aproveitaram a oportuni- 
dade para "virar a mesa" e usar o episódio como o pretexto que faltava para repudiar qualquer conciliação. Dois dias antes, a delegação argentina já havia protagonizado um lance teatral na Comissão, levantando-se e abandonando o recinto enquanto eram votadas conclusões pontuais do parecer Huneeus. $\mathrm{O}$ incidente da controvertida carta gerou nova onda de mal-estar generalizado contra o Brasil e atingiu pesadamente também o Chile, acusado desta vez de "traição" pela imprensa argentina, para desgosto e fúria de Alessandri. O Chile aparecia como se tivesse feito jogo duplo, ludibriando a Argentina desde o início, o que obrigou a chancelaria chilena a divulgar um comunicado dando a sua versão dos fatos. Alguns jornais chilenos pediram que Gurgel do Amaral fosse chamado de volta pelo governo brasileiro depois de sua "infeliz intervenção” na Comissão de Armamentos. ${ }^{23}$ A partir daí, não haveria clima negociador para nenhum outro acordo em Santiago.

\section{AS REPERCUSSÕES PÓS-SANTIAGO}

\subsection{Ainda as relações entre os países do $A B C$}

O encerramento formal da Conferência se deu em 3 de maio, com uma sessão especial na Câmara dos Deputados chilena, ocasião em que foi assinado o Tratado para evitar ou prevenir conflitos entre os Estados americanos, que ficaria conhecido como Pacto Gondra, em referência ao delegado paraguaio responsável pela iniciativa. ${ }^{24} \mathrm{~A}$ delegação brasileira colaborou ativamente nas negociações que resultaram naquele Tratado. Esse seria um meio de mostrar que o Brasil estava realmente comprometido com a paz na região (o que muitos já punham em dúvida), e que também estava disposto a cooperar construtivamente para esse nobre fim. Se a Conferência havia falhado como prévia regional das discussões gerais sobre o desarmamento em nível universal, pensava-se, o novo Tratado bem poderia servir como exemplo do espírito de conciliação prevalecente nas Américas, ao contrário do que sucedia na Europa, mostrando quão efetivo e progressista ainda era o pan-americanismo. Ainda durante o encerramento, Melo Franco declarou a propósito dos armamentos que o governo do Brasil estava pronto, "em qualquer ocasião", a exibir o quadro de seu aparelhamento militar e naval, perante a autoridade designada, "sem a menor reserva mental." Negou que a Conferência tivesse fracassado e enalteceu, como prova disso, a "obra duradoura" do Pacto Gondra, considerado o principal resultado concreto de Santiago. ${ }^{25}$

A imprensa no Brasil, que acompanhou a Conferência com certo distanciamento, teve avaliações díspares dos resultados da reunião. Os jornais sim- 
páticos ao governo federal procuraram ressaltar a "confraternização americana" presente nos discursos oficiais. O Paiz elogiou o "abençoado projeto" do Pacto Gondra, sinal dessa concórdia continental. Outros jornais não foram tão benevolentes. O Imparcial comentou sarcasticamente que o Brasil estava se afastando da tradição diplomática pacifista do país, pois os delegados brasileiros tinham ido a Santiago apenas com o desejo de "embrulhar os adversários." O jornal A Pátria arriscou dizer que o Brasil havia saído de "uma das mais delicadas crises internacionais registradas na nossa história diplomática." A lição da Conferência, ensinou o matutino carioca, era a revivescência do nacionalismo a guiar a conduta dos Estados: os egoísmos nacionais estavam "em positiva ascendência sobre as utopias de uma solidariedade geográfica." ${ }^{26}$

Em seu retorno do Chile, a delegação do Brasil passou novamente em escala por Buenos Aires, apesar da oposição de alguns delegados, que temiam possíveis demonstrações públicas de hostilidade. Coube a Melo Franco a decisão de manter o roteiro original para não dar sinais ostensivos de ressentimento pela recente atitude da Argentina na refrega de Santiago. Na capital argentina, o chefe da delegação brasileira foi convidado por Alvear para um jantar na residência presidencial. Não tendo sido alcançado um acordo em Santiago, Alvear propôs confidencialmente uma conversação sobre armamentos entre o Brasil e a Argentina, em local de comum acordo, por meio de algum "agente confidencial de cada lado", a fim de não deixar "constância dos fatos" caso fracassasse o entendimento bilateral. A eventual persistência de desacordo em nada afetaria as relações de amizade entre os dois países, porque os governos respeitariam os motivos da divergência e a confidencialidade afastaria o perigo de conjecturas pessimistas da imprensa, suscetíveis de influenciar a opinião pública. Desse entendimento, porém, não faria parte o Chile, pois sua entrada no convênio complicaria o assunto e tornaria mais difícil a solução. A iniciativa argentina parecia mesmo ter por finalidade tomar a frente do Chile, caso aquele país resolvesse ressuscitar a idéia da reunião de cúpula em Montevidéu, a qual permaneceu latente ao longo de toda a Conferência, sem ter sido jamais levada a público.

Melo Franco transmitiu o recado de Alvear em carta reservada a Artur Bernardes, datada de 28 de junho de 1923, na qual aproveitou para comentar sua ação na Conferência de Santiago. "Não obstante o absurdo da idéia", escreveu Melo Franco, "o fato é que se criou para o Brasil a fama de nação prussianizada, imperialista, com ambições de hegemonia na América Latina e preocupada, antes de tudo, com o problema do seu Exército e de sua Marinha." O único meio a empregar para pôr fim a essa "mentira", defendeu, era aquele adotado pela delegação do Brasil, isto é, não aceitar nenhum convênio sobre a questão dos armamentos, como deliberação coletiva da Conferência, 
mas não silenciar no debate da tese XII, participando dos trabalhos da comissão respectiva. Sobre a proposta de Alvear, Melo Franco foi taxativo: "Penso que não devemos ultimar ajuste algum com a Argentina sem dar conhecimento prévio ao Chile." O abandono da fórmula tripartite em favor do bilateralismo não seria conveniente para o Brasil, mesmo que o Chile já não fosse mais um aliado estratégico fundamental desde os chamados "Pactos de Maio", conjunto de acordos assinados entre a Argentina e o Chile, em 1902, sobre limites e reivindicações territoriais entre os dois países. ${ }^{27}$

Desse modo, vista com ressalvas pelo governo brasileiro por excluir o Chile da equação, a proposta de entendimento direto Brasil-Argentina não foi adiante. Afinal, em encontro à margem da Conferência entre o chefe de Estado-Maior do Exército, general Tasso Fragoso, e seu colega chileno, general Luis Brieba, este havia deixado a entender que, em caso de guerra entre a Argentina e o Brasil, o Chile ficaria do lado brasileiro. Claro está que nenhum dos dois países pretendia realmente iniciar um conflito armado, mas a suspeita recíproca alimentava receios de parte a parte. Para Melo Franco, a maioria do povo argentino não queria a guerra com o Brasil: "Não deseja a guerra, mas vive em uma constante desconfiança de que nós a provocaremos. É este também o estado de espírito público no Brasil." ${ }^{28}$

\subsection{Os Estados Unidos e o equilíbrio Brasil-Argentina}

Na América do Sul, a grande questão que se apresentava era a velha política do equilíbrio de poder entre o Brasil e a Argentina, dado o risco de que, na visão predominante da época, fosse desencadeada uma corrida armamentista na região. O chamado "dilema da segurança" explicaria em parte por que a Argentina, em função dos eventos ligados a Santiago, acelerou seus próprios planos de reaparelhamento naval. Em junho de 1923, o presidente Alvear enviou mensagem ao Congresso argentino solicitando sanção para projeto de lei que autorizava investimentos de 9,5 milhões de pesos-ouro na modernização da Marinha argentina, incluindo consertos de navios, compras de material e aquisição de novas unidades.

O governo Bernardes procurou, da mesma forma, levar a cabo novo programa de construção naval, com base em recomendações do chefe da Missão Naval norte-americana, almirante Carl Vogelgesang, plano que iria chocar-se com a orientação do governo dos Estados Unidos. Em 20 de maio de 1924, a pedido do governo brasileiro, Vogelgesang redigiu um memorando ao ministro da Marinha, almirante Alexandrino de Alencar, sugerindo um programa de reaparelhamento pelo prazo de dez anos. Nesse período, o Brasil teria uma 
força naval tática e estrategicamente "bem equilibrada e eficiente." O programa proposto compreendia a seguinte tonelagem: submarinos, 6.000 ; contratorpedeiros, 15.000; cruzadores, 60.000; e navios de combate, 70.000 toneladas. A prioridade na construção deveria ser atribuída aos submarinos (6 unidades de 1.000 toneladas cada uma), seguidos dos contratorpedeiros. Os navios de combate deveriam substituir os atuais encouraçados quando estes atingissem o fim de sua vida útil. ${ }^{29}$

Ao ser informado da existência desse memorando, que seria submetido ao presidente da República, o Departamento de Estado reagiu com invulgar altercação. Hughes telegrafou à embaixada norte-americana, em 11 de junho de 1924, dando conta que o programa naval recomendado por Vogelgesang era "muito perturbador." Mesmo se de um ponto de vista puramente técnico o programa pudesse ser justificável, o gasto envolvido parecia "exorbitante e fora de proporção" em vista das necessidades de um país como o Brasil, "que não era ameaçado de lugar nenhum". A política cardeal do governo norteamericano para a América Latina, asseverou o secretário de Estado, era a paz e a promoção de relações amigáveis entre os países latino-americanos. Provavelmente tendo a lembrança dos protestos argentinos em 1922, Hughes assinalou que implementar o programa naval na escala sugerida daria ampla justificação às críticas que haviam sido dirigidas à Missão.

Pouco depois, Hughes insistiu que a implementação do programa brasileiro tornaria necessário à Argentina e ao Chile elaborar programas navais equivalentes, iniciando assim uma competição nessa área. O secretário de Estado dizia não saber por qual potência o Brasil estava ameaçado "para necessitar de tão grande frota defensiva." E continuou: "O sentimento do Departamento sobre o assunto é tão forte que preferiríamos chamar de volta a Missão Naval a assumir a responsabilidade pelo programa naval proposto pela Missão." Hughes solicitou que, na primeira oportunidade, Vogelgesang revisasse o programa com base no princípio de que nenhuma construção nova ou substituição de tonelagem em qualquer categoria seria maior do que o máximo já existente no momento em qualquer um dos três países do ABC. Assim, seguindo a orientação do Departamento de Estado, as recomendações da Missão Naval ao governo brasileiro foram retiradas para revisão. Na versão revista dessas recomendações, todas as referências a um programa concreto de construção ou sugestões com relação a tonelagem, tipos de navios e número de unidades foram canceladas e omitidas. ${ }^{30}$

O abortado programa naval de 1924 de Vogelgesang serviu de qualquer modo para revelar a concepção estratégica da Missão Naval do ponto de vista do governo norte-americano. Ao contrário da França, que com sua Missão Militar pretendia basicamente auferir ganhos comerciais imediatos, os Esta- 
dos Unidos se guiavam por considerações políticas de alcance mais longo, alicerçadas na manutenção de uma política perene de equilíbrio entre as principais potências da América do Sul. Os Estados Unidos não iriam privilegiar parceiros, selecionando "aliados especiais" em detrimento de outros países. Qualquer esperança do Brasil de obter tratamento diferenciado haveria de ser rebatida em virtude do quadro mais amplo da política sul-americana dos Estados Unidos e do papel-chave atribuído pelo Departamento de Estado à Argentina na preservação da balança de poder na região.

\section{CONCLUSÃO}

O Brasil havia ido a Santiago com dois objetivos principais: preservar a paz com seus vizinhos e ao mesmo tempo salvaguardar sua autonomia para modernizar e reequipar suas forças armadas no interesse da defesa nacional. Tasso Fragoso, uma voz de muita influência entre os militares brasileiros, assinalou de modo bastante franco essa dualidade de propósitos: "Não somos povo conquistador, nem alimentamos projetos agressivos, mas temos um patrimônio sagrado a zelar. Devemos repelir, como certamente o fariam argentinos e chilenos, todas as combinações que tolham a nossa liberdade." ${ }^{31}$

Com base em auto-avaliação bastante negativa das capacidades brasileiras na área de defesa, o Brasil adotou um curso de ação que implicava na prática um custo político considerável no âmbito regional. Sob o risco de enfrentar externamente críticas e resistências, a diplomacia brasileira procurava traduzir nos foros multilaterais a percepção interna de insuficiência e inadequação das forças militares de que dispunha o país. Melo Franco costumava dizer que, proporcionalmente à população do país e levando em conta a extensão do território nacional, o Exército brasileiro era o mais reduzido das Américas, com exceção apenas do Panamá.

Seja como for, as negociações em torno dos armamentos navais após a Primeira Guerra Mundial, influenciadas por expectativas idealistas quanto a seus possíveis resultados, encobriam uma dupla ironia: nem os Estados no plano internacional estavam dispostos àquela altura a levar o desarmamento às suas últimas conseqüências, nem os países do $\mathrm{ABC}$ detinham recursos financeiros ou motivos concretos para perseguir uma política que implicasse gastos militares crescentes e investimentos pesados nessa área. No Brasil, por dificuldades tanto políticas quanto orçamentárias, nenhum dos grandes projetos concebidos para reaparelhar a Marinha brasileira seria cumprido na década de 1920.

Em Santiago, a despeito das acaloradas negociações de bastidores e da 
repercussão política da questão dos armamentos, a discussão da tese XII foi, em certo sentido, um exercício de diplomacia em torno de possibilidades teóricas que poderiam ou não se materializar no futuro. Em comparação com as grandes potências européias, por exemplo, os países da América do Sul detinham então uma fração minúscula da ativa dos exércitos e das forças organizadas militarmente.

A conclusão mais pertinente, portanto, não seria apontar quais dos países sul-americanos se apresentavam mais ou menos armados. Para a diplomacia brasileira, a grande lição da Conferência residiu na constatação de que o Brasil estava virtualmente isolado no continente. Os apoios recebidos dos países vizinhos foram escassos. A Argentina, verificou-se, havia tirado proveito da peculiaridade da posição brasileira para fazer propaganda da vertente principista de sua política externa e reforçar suas credenciais como líder regional. Nem o Chile, o tradicional "amigo no Pacífico", parecia de todo confiável. Observando tudo à distância, os Estados Unidos tampouco prestaram a assistência que o Brasil esperava.

O problema era de fundo e na verdade se agravou ao longo do governo Artur Bernardes, cujas atenções iriam concentrar-se quase por completo na tentativa (frustrada) de obter um assento permanente para o Brasil no Conselho da Liga das Nações. Foi somente a partir de 1927, já no governo Washington Luís, que uma revisão de prioridades haveria de ser produzida com o fito de inaugurar uma nova fase nas relações entre o Brasil e a América do Sul, da qual não mais fizessem parte rixas desgastantes ou desinteligências surdas, como aquelas que marcaram o conclave de Santiago. ${ }^{32}$

\section{NOTAS}

${ }^{1}$ Não há estudos históricos recentes sobre a participação brasileira na Conferência PanAmericana de 1923. LOBO, Hélio abordou o tema em O pan-americanismo e o Brasil. São Paulo: Companhia Ed. Nacional, 1939, pp.85-95. Afonso Arinos, na biografia sobre o pai, dedicou um capítulo à Conferência: MELO FRANCO, A. A. de. Um estadista da República: Afrânio de Melo Franco e seu tempo. Rio de Janeiro: Livraria José Olympio Editora, 1955, vol. III, pp.1.113-1.162. Para uma visão geral ver INMAN, Samuel Guy. Inter-American conferences, 1826-1954: history and problems. Washington: University Press of Washington, 1965, pp.88-105. As opiniões expressas neste artigo são de responsabilidade exclusiva do autor e não refletem necessariamente posições da instituição à qual se encontra vinculado.

${ }^{2}$ VIDIGAL, Armando A. F. A evolução do pensamento estratégico naval brasileiro. Rio de Janeiro: Biblioteca do Exército, 1985, pp.59-61; LIVERMORE, Seward W. Battleship diplo- 
macy in South America, 1905-1925. The Journal of Modern History, vol. 16, $\mathrm{n}^{\circ}$ 1, March 1944, pp. 31-48.

3 "Situação militar na Sul América: Estudo comparativo dos orçamentos da Guerra para 1922 do Brasil e Argentina”, Estado-Maior do Exército, secreto, Rio, 12 dez. 1922, p. 6, Biblioteca Nacional (BN), Coleção Afrânio de Melo Franco (AMF), Pasta 650; BURLAMAQUI, Armando C. A situação naval sul-americana em 1921. Rio de Janeiro: Imprensa Naval, 1922, p.IV e p.53; e, do mesmo autor, Esboço da política naval brasileira. Rio de Janeiro: Imprensa Nacional, 1923, p.24.

${ }^{4}$ Pessoa a Gama, tel., Rio, 17 set. 1922, Arquivo Histórico do Itamaraty, Rio de Janeiro (doravante AHI) 274/2/4; Marques a Gama, tel., Rio, 4 ago. 1922, AHI 219/3/4; Relatório apresentado ao presidente da República pelo ministro de Estado das Relações Exteriores relativo ao ano de 1923. Rio de Janeiro: Imprensa Nacional, pp.18-19.

5 "As Conferências de Washington e Santiago, a limitação dos armamentos e a situação internacional do Brasil", documento reservado, Santiago, 8 abr. 1923, BN, Coleção AMF, Pasta 53 , passim.

${ }^{6}$ Pacheco a Alencar, tels., Rio, 20, 21 e 28 nov. 1922, AHI 235/4/5; Pacheco a Dantas, tel., Rio, 29 dez. 1922, AHI 227/4/2.

${ }^{7}$ Pacheco a Alencar, tel., Rio, 24 nov. 1922, AHI 235/4/5; Pacheco a Toledo, tel., Rio, 28 nov. 1922, AHI 208/3/1; Alencar a Pacheco, tel., Washington, 30 nov. 1922, AHI 235/3/13.

${ }^{8}$ Quatriênio Artur Bernardes (1922-1926). Rio de Janeiro: Jornal do Commercio, 1926, p.92; Toledo a Pacheco, tel., reservado, Buenos Aires, 2 dez. 1922, AHI 208/2/1.

${ }_{9}^{9}$ Quatriênio Artur Bernardes, op.cit. pp.90-91; Toledo a Pacheco, tel., Buenos Aires, 7 dez. 1922, AHI 208/2/1. A resposta do Chile, redigida em termos amistosos, em nada acrescentou à questão, dada a impugnação da iniciativa pela Argentina. Cf. ÁVALOS, Angel F. El proyecto brasileño de Conferencia Internacional de Valparaíso: estudio sobre política internacional y militar entre Brasil y la Argentina. Córdoba: Bautista Cubas, 1923, pp.203-210.

10 "La proposición brasileña”, Jorge A. Mitre, La Nación, Buenos Aires, 7 dez. 1922, AHI 206/4/8; "Redución de armamentos, La propuesta brasileña”, La Razón, Buenos Aires, 7 dez. 1922, AHI 206/4/8.

${ }^{11}$ Pacheco a Toledo, tel., Rio, 14 dez. 1922, AHI 208/3/1; Pacheco a Gama, tel., Rio, 30 dez. 1922, AHI 219/3/4; Tilley a Curzon, tel., Rio, 9 jan. 1923, In: BOURNE, K. \& WATT, D. C. British documents on foreign affairs: reports and papers from the Foreign Office Confidential Print. Bethesda: University Publications of America, Part II, Series D, vol. 3, pp.136-137.

${ }^{12}$ Riddle a Hughes, tel., Buenos Aires, 20 dez. 1922, In: Papers relating to the foreign relations of the United States. Washington: Government Printing Office, 1922, vol. I, p.655; Riddle a Hughes, ofício, Buenos Aires, 20 dez. 1922, National Archives and Records Administration (doravante apenas NA), College Park, MD (EUA), State Department Central Files (Record Group 59), 832.30/97; Mallet a Curzon, tel., Buenos Aires, 22 dez. 1922, e Als- 
ton a Curzon, tel., Buenos Aires, 31 dez. 1922, ambos In: British documents on foreign affairs, op.cit. Part II, Series D, vol. 3, pp.134-135.

${ }^{13}$ Hughes a Riddle, tel., Washington, 21 dez. 1922, In: Papers relating to the foreign relations of the United States, op.cit., 1922, vol. I, pp.655-656; Hughes a Riddle, despacho, Washington, 17 jan. 1923, NA 832.30/97.

${ }^{14}$ Cf. Relatório do MRE, 1924. Anexo A, p.110-121. Além de Melo Franco, os outros delegados brasileiros eram Silvino Gurgel do Amaral, James Darcy, José de Paula Rodrigues Alves, Hélio Lobo e Alberto Jorge de Ipanema Moreira. A comissão militar que acompanhava a delegação era encabeçada pelo próprio chefe de Estado-Maior do Exército, general-de-divisão Augusto Tasso Fragoso, enquanto a chefia da comissão naval cabia ao contra-almirante Augusto Carlos de Souza e Silva. Ver Relatório do MRE, 1923. pp.23-26 e pp.98-99. Em 1923, ao final dos trabalhos em Santiago, Melo Franco escreveu um relatório de 119 páginas (doravante Relatório AMF) sobre a participação do Brasil na V Conferência Internacional Americana, BN, Coleção AMF, Pasta 415.

${ }^{15}$ Relatório AMF, op.cit. p.2; Melo Franco a Pacheco, tel. confidencial, Santiago, 25 mar. 1923, AHI 273/3/16.

${ }^{16}$ Pacheco a Melo Franco, tel., Rio, 26 mar. 1923, AHI 273/3/16.

${ }^{17}$ MELO FRANCO. Um estadista da República, op.cit., vol. III, p.1130; "El origen de la militarización brasileña”, La Prensa, Buenos Aires, 31 mar. 1923, AHI 206/4/9.

${ }^{18}$ Relatório AMF, op.cit. p.14.

${ }^{19} \mathrm{Na}$ mesma sessão, o delegado do Paraguai, Manuel Gondra, lançou a idéia de um tratado continental para a prevenção da guerra, proposta igualmente apoiada pela delegação brasileira. Uma subcomissão foi apontada para estudar o assunto em separado, da qual Melo Franco faria parte em nome do Brasil. Idem, pp.35-37.

${ }^{20}$ Amaral a Pacheco, tel., Santiago, 26 abr. 1923, AHI 231/4/13; Pacheco a Melo Franco, tel. urgente, Rio, 21 abr. 1923, AHI 273/3/16.

${ }^{21}$ Declaração de Princípios feita pelo chefe da delegação brasileira na sessão de 21 de abril de 1923 da Comissão de Armamentos, Relatório do MRE, 1924. Anexo A, pp.144-156.

${ }^{22}$ BURLAMAQUI. Esboço da política naval brasileira, op.cit. pp.43-45; Melo Franco a Pacheco, tel., Santiago, 25 abr. 1923, AHI 273/3/16.

${ }^{23}$ MELO FRANCO. Um estadista da República, op.cit., vol. III, pp.1.145-1.147; Stewart a Curzon, tel., Rio, 7 maio 1923, In: British documents on foreign affairs, op.cit. Part II, Series D, vol. 3, pp.181-182; La Prensa, Buenos Aires, 8 jun. 1923, AHI 206/4/10.

${ }^{24} \mathrm{O}$ Tratado estabelecia que toda a questão entre dois ou mais Estados americanos que não pudesse ser resolvida pela via diplomática ou pelo arbitramento seria submetida a uma "comissão investigadora", encarregada de estudar a questão em apreço. Em caso de conflito, os signatários do tratado se obrigavam a não tomar medidas de preparação militar nem 
iniciar hostilidades antes de ser conhecido o relatório daquela comissão, após o que os Estados não poderiam entrar em guerra pelo prazo de seis meses, período adicional para se buscar uma solução da dificuldade. MELO, Rubens Ferreira de. Textos de direito internacional e de história diplomática de 1815 a 1949. Rio de Janeiro: A. Coelho Branco Filho Editor, 1950, pp.262-266.

${ }^{25}$ Relatório do MRE, 1924. Anexo A, p.156-161; MELO FRANCO. Um estadista da República, op.cit., vol. III, pp.1.153-1.157.

26 "Um hino à fraternidade continental", O Paiz, Rio, 7 maio 1923; "O Brasil na Conferência de Santiago", O Imparcial, Rio, $1 \infty$ abr. 1923; "A lição da Conferência", A Pátria, Rio, 18 maio 1923; BN Coleção AMF, Pastas 454 e 652.

${ }^{27}$ Segundo Melo Franco, "politicamente falando" o Chile havia perdido muito da importância que tinha para o Brasil antes daqueles acordos com a Argentina. Relatório AMF, op.cit., pp.96-97; Melo Franco a Bernardes, carta reservada, Rio, 28 jun. 1923, BN, Coleção AMF, Pasta 2.

28 "A questão dos armamentos na Conferência de Santiago, relatada pelo Estado-Maior do Exército", absolutamente secreto, Rio, 1923, BN, Coleção AMF, Pasta 206; Relatório AMF, op.cit., p.111.

${ }^{29}$ La Nación, Buenos Aires, 17 jun. 1923, AHI 206/4/10; Morgan a Hughes, ofício, Rio, 25 200 jun. 1923, NA 832.34/178; “Memorandum for the Minister of Marine”, 20 maio 1924, C. T. Vogelgesang, NA 832.20/38; Crosby a Hughes, tel., Rio, 6 jun. 1924, NA 832.34/182.

${ }^{30}$ Hughes a Crosby, tels., Washington, 11 e 26 jun. 1924, NA 832.34/183 e 185; Crosby a Hughes, tel., Rio, $1 \infty$ jul. 1924, NA 832.34/186. Ver também Papers relating to the foreign relations of the United States, op.cit., 1924, vol. I, pp.323-327.

${ }_{31}$ "Situação militar na Sul América", op.cit., p.8, BN, Coleção AMF, Pasta 650.

${ }^{32}$ Em alentado estudo elaborado pelo Itamaraty, Ronald de Carvalho havia sido taxativo quanto à situação de isolamento diplomático do Brasil: "Estamos abandonados, neste continente, onde outrora fomos respeitados, porque nos deixamos enfraquecer paulatinamente." Como forma de reverter esse quadro, propunha-se uma política sustentada de reaproximação com os países sul-americanos a fim de restaurar o status brasileiro na região. CARVALHO, Ronald de. Relatório reservado sobre a política exterior do Brasil e dos países da América do Sul. Rio de Janeiro, 1927, mimeo, p.150. Sobre a questão da Liga, ver GARCIA, Eugênio V. O Brasil e a Liga das Nações (1919-1926): vencer ou não perder. Porto Alegre/Brasília: Editora da Universidade (UFRGS) e Fundação Alexandre de Gusmão, 2000.

Artigo recebido em 4/2003. Aprovado em 10/2003. 